Session 2666

\title{
Integration and Implementation of a Thermodynamics Instructional Software
}

\author{
Karim J. Nasr \\ Mechanical Engineering Department \\ GMI Engineering \& Management Institute \\ Flint, MI 48504
}

\begin{abstract}
This paper presents the integration and implementation of Mathcad's Electronic Book titled "Thermodynamics for Engineers" into a first course on Engineering Thermodynamics at GMI Engineering \& Management Institute. This instructional computer software utilizes Mathcad tools and exhibits worked-out problems in Thermodynamics. The purpose of such implementation is to enhance students' understanding of fundamental concepts by interactively retrieving thermodynamic properties, performing parametric investigations, and creating models of thermodynamic systems. The process of integrating the software into the course, supported by students experiences and comments, is outlined and helpful practices for its implementation are presented.
\end{abstract}

\section{INTRODUCTION \& MOTIVATION FOR USING THE SOFTWARE}

Computer tools have become an integral part of engineering education (Gidh and Hanyak,1993; Braun et al., 1996; and Bowman, 1996). Such tools have gained general acceptance and have been implemented and integrated into various engineering courses. Pattee (1995) states that "In engineering schools throughout the country, students are now being introduced to Maple, Mathematica, Mathcad, Matlab, and other mathematical software as early as their freshman year." The Thermal Sciences Committee of the Mechanical Engineering Department at GMI Engineering \& Management Institute purchased Mathcad modules in Engineering Thermodynamics to be implemented in the classroom targeting design-oriented problems and enhancement of students' understanding of fundamental concepts in Thermodynamics. Traditionally, students in a first course on Engineering Thermodynamics get frustrated with phase diagrams and finding thermodynamic properties for compressible pure substances (superheated vapors, compressed liquids, and mixtures of liquid and vapor), ideal gases, and incompressible substances (solids and liquids). Instructors, on the other hand, allocate a sizable and valuable amount of time explaining the retrieval process of these properties and the establishment of a thought process. Students who get proficient in properties finding, have no trouble dealing with the first and second laws of Thermodynamics and often cruise through cycles analysis focusing on fundamental concepts. Thus, the objective is to utilize Mathcad modules in speeding the process of retrieving properties, in expanding students' knowledge base, and in adding a design flavor to the course. The goal of this paper is to outline the process of integration and implementation of the software and to present some of the lessons learned. 


\section{ELECTRONIC BOOK HIGHLIGHTS}

Key features of Mathcad's Electronic Book (MathSoft, Inc.) on Engineering Thermodynamics are highlighted by:

1. Using Mathcad tools interactively with "Live Math"

2. Providing equation-solving tools supported by tool bars, buttons, and palettes

3. Performing arithmetic with built-in functions and mathematical operators

4. Defining variables and functions, and evaluating functions and expressions over ranges

5. Plotting and visualizing data in two and three dimensions

6. Providing worked-out problems as complete solutions by displaying a problem statement, system parameters and a step-by-step solution with numerical answers

7. Using consistent system of units, providing the user with the option of changing the system of units and computing the parameter of interest for the changed system of units

8. Presenting helpful diagrams for most worked-out problems

9. Using underlined hypertext links to browse through various sections

10. Utilizing each problem as a "worksheet" which can be modified to solve related problems.

\section{INTEGRATION \& IMPLEMENTATION}

Besides reasons such as working in teams and getting students familiar with computer packages, students were instructed to utilize this electronic book in an effort to strengthen their understanding of the topic and expand on fundamental concepts by examining the effect that one variable might have on the solution of a problem. This paper is not focused on presenting specific examples which would illustrate the use of this software (the reader is referred to the worked-out problems in the software), nor is it focused on the explicit use of its highlights. The goal of this paper is then to highlight the steps taken in implementing and integrating this Electronic book into our first course on Engineering Thermodynamics.

Students were first given clear instructions on how to log onto a PC and get the windowsbased software running. They were also instructed to go through the Mathcad tutorial provided within the Electronic Book. Students normally spend the first week of the course going through the tutorial and getting familiar with the software contents. At the end of the first week, students were asked to provide their initial feedback (impression) on the software and document what they have learned. Generally, students were impressed by the front end of the software which exhibits the tool bar, the various buttons and commands, and the palettes. However, the tutorial was perceived as lacking in applying the commands to the field of thermodynamics. In a typical term, students were normally assigned a total of fourteen computer problems (seven Mathcad assignments) and a design project, in addition to their usual weekly homework assignments extracted from their textbook. The design project is a new addition to this course and students were encouraged to utilize the software's capabilities to accomplish their task. These Mathcad assignments were made mandatory while some of the textbook homework problems of similar objective (or dealing with the same concept) were made optional. Table 1 tabulates the integration process and presents a sample of assigned computer problems and their objectives. Table 1. Sample computer assignments and their objectives 


\begin{tabular}{|l||l||}
\hline \multicolumn{1}{|c||}{ Computer Problems } & \multicolumn{1}{c|}{ Objectives } \\
\hline \hline $\begin{array}{l}\text { Select your own thermodynamic state of a } \\
\text { pure compressible substance, an ideal gas, } \\
\text { and an incompressible substance }\end{array}$ & $\begin{array}{l}\text { Exposure to Mathcad programming language } \\
\text { Retrieval of thermodynamic properties }\end{array}$ \\
\hline $\begin{array}{l}\text { First law for a closed system } \\
\text { Polytropic process }\end{array}$ & $\begin{array}{l}\text { Parametric studies: The effect of the } \\
\text { polytropic exponent, } \mathrm{n} \\
\text { Computation and plotting heat and work for } \\
\text { the various values of } \mathrm{n}\end{array}$ \\
\hline First law on an open system (turbine) & $\begin{array}{l}\text { Parametric investigations: effect of variable } \\
\text { inlet pressure, inlet temperature, and exit } \\
\text { pressure. } \\
\text { Computerized properties finding } \\
\text { Relative contributions of energy terms: kinetic } \\
\text { energy change/potential energy change } \\
\text { relative to rate of heat transfer and power } \\
\text { produced }\end{array}$ \\
\hline $\begin{array}{l}\text { Otto and Diesel Cycles } \\
\text { Second law analysis and entropy } \\
\text { generation }\end{array}$ & $\begin{array}{l}\text { compression ratios } \\
\text { Graphing heat added and compression ratio } \\
\text { versus efficiency }\end{array}$ \\
\hline $\begin{array}{l}\text { Computation and plotting of mass flow rates } \\
\text { through steam generators and entropy } \\
\text { produced versus variable output power }\end{array}$ \\
\hline
\end{tabular}

Students Feedback: Based on students' experience with the software for the last year and a half, the success in implementing and integrating this software into a typical undergraduate course in Thermodynamics is tied directly to the extent of students' knowledge of Mathcad. Most students often expressed a high level of early frustration originating from their lack of familiarity with Mathcad. Students who had prior exposure and experience with Mathcad were more patient and showed signs of strong desire to experiment with the software. Students appreciated the software's objective and focused nature of worked-out problems and the logical and systematic manner by which the problems are exhibited. Students were traversing familiar ground as they used the underlined hypertexts because the software's table of contents reflects the standard material coverage of an undergraduate course in Thermodynamics.

Helpful Practices for Implementation: One must not underestimate the importance of facultystudent contact, for it sets the tone for students' drive to experiment with the software. It also provides the instructor with prompt and "fresh" feedback. Students greatly appreciated an initial help session on using the software. This initial help session reduces their time investment in learning the package (learning curve) and smoothes the way for exploration and development of cognitive skills. Cooperation among students (working in small teams) can ease the transition for some students and helps provide an active learning environment. Also, the time a student spends on an assignment must be estimated and evaluated carefully because a long and time consuming assignment can generate frustration and affects students' work load on other courses. 
Early exposure (in a previous course for example) to such mathematical tool can mean the difference between successful implementation or otherwise. Keeping these practices in mind generated a level of excitement among thermodynamics students. Students did not feel left alone, subject to excessive level of frustration, noticed the usefulness of the software, and projected its potential use for other courses and related projects.

\section{CONCLUSIONS}

The following conclusions can be drawn from the experience of integrating and implementing this instructional software into the thermodynamics course:

1. The success in integrating and implementing the software is linked to the extent of students' prior exposure to the mathematical tool.

2. The time investment in learning the software can be shortened by incorporating helpful practices during implementation such as obtaining prompt feedback, providing an active environment, working in small teams, allocating appropriate time for assignments, and providing constant faculty-student interaction.

3. In retrieving thermodynamic properties from the computerized tables and graphs, it is believed that the user may lose concentration of thermodynamics and become absorbed by what is required to be done using Mathcad Programming language.

4. With relatively little knowledge of Mathcad programming, a single input parameter can be varied over a certain range as well as providing the user with the capability to create iterations which evaluate the system for a variety of input values.

5. As far as the ability of the user to create his/her own models of thermodynamic systems, a close match in input/output is needed between the user-created model and one of the worked-out examples.

\section{REFERENCES}

Bowman, K. J., "Mathcad Modules for Materials Engineering Education," Proceedings of ASEE, Illinois-Indiana Section Conference, Session 1E4, Purdue University, West Lafayette, Indiana, 1995, 93 - 96.

Braun, J. E., Frankel, S. H. and P. E. Sojka, "Integrating Equation Solving Software into Undergraduate Thermodynamics," Proceedings of ASEE, Illinois-Indiana Section Conference, Session 3D1, Purdue University, West Lafayette, Indiana, 1995, 273 - 277.

Gidh, K. and M. E. Hanyak Jr., “A Thermodynamics Teaching Aid for Undergraduate Engineers,” Int. J. Engng. Ed. Vol. 9, No. 2, 1993, 162 - 185.

MathSoft, Inc., Mathcad Educational Licensing, Edited by: M. C. Potter and C. W. Somerton, Cambridge, MA 02142.

Pattee, H. A., "Selecting Computer Mathematics,” Mechanical Engineering, September 1995, 82-84.

\section{BIOGRAPHICAL INFORMATION}

Karim J. Nasr: Dr. Nasr is an assistant professor at GMI Engineering \& Management Institute. His area of expertise is Thermal Sciences. His current activities involve teaching Thermodynamics, Fluid Mechanics, and Heat Transfer, developing new courses, and performing experimental and numerical investigations on fluid flow and thermal problems. 